\title{
Which foods are the strongest predictors of dietary fibre consumption in children aged 6 to 7 years?
}

\author{
C. E. L. Evans and J. E. Cade \\ Nutritional Epidemiology Group, School of Food Science and Nutrition, University of Leeds, Leeds, UK
}

High fibre diets are associated with positive health outcomes in adults such as a reduction in risk of obesity, type 2 diabetes and some cancers. $^{(1-3)}$ The recommended daily intake of non-starch polysaccharides (NSP) for adults is $18 \mathrm{~g}$, however the population average is considerably lower than this at $13 \mathrm{~g} .{ }^{(4)}$ One reason for low intakes of fibre is that rich sources such as wholegrain foods and fruits and vegetables are not as popular as foods made from white flour. Encouraging high fibre foods from childhood may help to increase consumption over the life course and identification of which foods make a significant contribution to fibre intakes in childhood may assist in developing appropriate health promotion directives.

This analysis uses data collected in 2007 as part of a large trial named Project Tomato commissioned by the MRC. Dietary data were collected from 2709 children aged 6 to 7 years in 129 schools across England. Frequency of consumption of 16 foods over one 24 hour period was collected using the CADET diary. Analysis was carried out on 2685 children after excluding 24 children with unfeasibly high values for energy intake (>5000 kcal/d). Mean daily NSP intake was $11.9 \mathrm{~g}$ (SE $0.13 \mathrm{~g}$ ). Regression analysis was carried out to determine the association between main food types and NSP intake using a model adjusted for clustering of children within schools and energy intake (model 1) and after additional adjustment for age, gender and deprivation (model 2). The results in Table 1 are reported as difference in grams of NSP with each portion of food consumed. There were no significant associations between NSP intake and frequency of consumption of pasta, rice, pizza, sweet pies, lower fibre breakfast cereals or muesli bars. NSP intake was significantly higher by 1 to $3 \mathrm{~g}$ with consumption of each portion of high fibre breakfast cereal, potatoes and fruit and vegetables. Fibre intake was significantly lower by 0.6 to $1.4 \mathrm{~g}$ with increased consumption of cakes, biscuits and crisps. These results indicate that to successfully promote a high fibre diet in children it is necessary to encourage consumption of fruit and vegetables and high fibre starchy foods and to reduce lower fibre starchy or salty foods.

Table 1: Predictors of fibre intake (NSP) in children with a range of foods

\begin{tabular}{|c|c|c|c|c|c|c|}
\hline Food & Coefficient Model 1 & $95 \% \mathrm{CI}$ & $P$ value & Coefficient Model 2 & $95 \% \mathrm{CI}$ & $P$ value \\
\hline High fibre cereal & 2.8 & 2.6 to 3.1 & $<0.001$ & 2.9 & 2.6 to 3.2 & $<0.001$ \\
\hline Potatoes & 1.2 & 0.9 to 1.6 & $<0.001$ & 1.3 & 1.0 to 1.7 & $<0.001$ \\
\hline Fruit and veg & 0.9 & 0.7 to 1.0 & $<0.001$ & 0.9 & 0.8 to 1.0 & $<0.001$ \\
\hline Chocolate bar & -1.3 & -1.7 to -0.9 & $<0.001$ & -1.2 & -1.6 to -0.8 & $<0.001$ \\
\hline Cakes & -1.4 & -1.9 to -1.0 & $<0.001$ & -1.4 & -1.8 to -0.9 & $<0.001$ \\
\hline Biscuits & -1.1 & -1.4 to -0.7 & $<0.001$ & -0.9 & -1.3 to -0.6 & $<0.001$ \\
\hline Crisps & -0.6 & -1.0 to -0.3 & $<0.001$ & -0.6 & -1.0 to -0.3 & $<0.001$ \\
\hline
\end{tabular}

1. Aune D, Chan DSM, Greenwood DC, et al. (2012) Dietary fiber and breast cancer risk: a systematic review and meta-analysis of prospective studies. Annals of Oncology.

2. de Munter JS, Hu FB, Spiegelman D, et al. (2007) Whole grain, bran, and germ intake and risk of type 2 diabetes: a prospective cohort study and systematic review. PLoS Med 4(8), e261.

3. Newby P. (2009) Plant foods and plant-based diets: protective against childhood obesity? The American Journal of Clinical Nutrition 89(5), 1572S-87S.

4. Health Do. National Diet and Nutrition Survey: Headline Results from Years 1, 2 and 3 (combined) of the Rolling Programme 2008/09-2010/11, 2012. 